\title{
SISTEMATIZAÇÃO DA ASSISTÊNCIA DE ENFERMAGEM: A VISIBILIZAÇÃO DO SER E FAZER PROFISSIONAL FACE À COVID-19 ${ }^{1}$
}

\author{
Ismar Filipe Rodrigues de Almeida ${ }^{2}$ \\ Juan Portella Braga Fogaca² \\ Regina Celia de Castro Gomes ${ }^{3}$ \\ Luciano Samaniego Arrussul ${ }^{4}$ \\ Dirce Stein Backes ${ }^{5}$
}

\section{RESUMO}

Objetivou-se discorrer sobre os passos da Sistematização da Assistência de Enfermagem, a partir de um relato de Enfermeiro da linha de frente da Covid-19, publicado em jornal local. Trata-se de um estudo qualitativo exploratório, realizado a partir da seleção de um depoimento de profissional de enfermagem que atua diretamente no combate à Covid-19. O depoimento da profissional Enfermeira foi extraído do site oficial da Unimed, no dia 17 de maio de 2020, dentre outros depoimentos públicos. A Sistematização da Assistência de Enfermagem fundamentada na teoria da complexidade é capaz de possibilitar, a partir de um olhar ampliado e prospectivo, reflexões que transcendem o ser e fazer enfermagem face às adversidades da pandemia da Covid-19. Para além do fazer enfermagem é preciso considerar o ser profissional que está exposto, continuamente, à medos, angústias e incertezas.

PALAVRAS-CHAVE: Enfermagem; Cuidados de Enfermagem; Coronavírus; Covid19.

EIXO TEMÁTICO: Atenção Integral e Promoção à Saúde (AIPS).

\footnotetext{
${ }^{1}$ Trabalho realizado na disciplina de Fundamentos Teórico-Filosóficos de Enfermagem do Curso de Enfermagem da Universidade Franciscana - UFN.

2 Estudantes do curso de enfermagem da Universidade Franciscana.

${ }^{3}$ Enfermeira. Aluna do Mestrado Profissional em Saúde Materno-Infantil da Universidade Franciscana - UFN.

${ }^{4}$ Enfermeira. Aluna do Mestrado Profissional em Saúde Materno-Infantil da Universidade Franciscana - UFN.

5 Doutora em Enfermagem. Professora da disciplina de Metodologia Científica, no Curso de Enfermagem da Universidade Franciscana - UFN. Orientadora do trabalho.
} 


\section{INTRODUÇÃO}

A Covid-19 é uma doença respiratória acometida pelo novo coronavírus (SarsCov-2), que vem fazendo vítimas em todos os cantos do mundo. O coronavírus teve seu primeiro registro de casos na cidade de Wuhan na china em dezembro de 2019. Não se sabe ao certo o seu contágio, mas ao que tudo indica é que as primeiras pessoas infectadas estiveram no mercado popular da cidade, no qual servem animais silvestres como iguarias. Com isso houve afirmações de que talvez esses animais ou algum deles estivessem infectados com o vírus e que teriam causado a infecção em humanos (CRODA; GARCIA, 2020).

A emergência do novo coronavírus vem afetando as pessoas e profissionais nas diferentes dimensões. Os mais afetados, no entanto, são os profissionais da saúde que vivenciam dia após dia a entrada de pacientes com sintomas de Covid-19. Além de altos níveis de estresse e desgastes físicos, os profissionais da saúde sentem-se comprometidos com o cuidado de seus familiares, ou seja, necessitam preservar a saúde pessoal e a de seus familiares (WU; LEUNG; LEUNG, 2020).

Uma das áreas profissionais diretamente envolvidas no combate ao Covid-19 é a Enfermagem. Com cerca de dois milhões de profissionais (enfermeiras/os, auxiliares e técnicos de enfermagem) diretamente envolvidos no combate à Covid-19, a Enfermagem requer a atenção e a proteção devida do Estado, além da devida garantia das condições de trabalho para o correto e seguro desempenho profissional na luta pela saúde da população e pelo direito à vida (SILVA, 2020).

A Sistematização da Assistência de Enfermagem (SAE) se constitui em uma ferramenta metodológica, com caráter científico, capaz de visibilizar a atuação do Enfermeiro, sobretudo, neste período pandêmico em curso. Além de visibilizar o processo de enfermagem, a SAE possibilita a coleta de dados pertinentes, 0 diagnóstico, o planejamento, a implementação e avaliação de enfermagem. Sob esse enfoque, a SAE deve se reafirmar como ferramenta metodológica para o favorecimento da identificação das necessidades de cuidados, planejamento e execução de intervenções que colaborem para desfechos favoráveis de indivíduos, famílias, grupos e comunidades no âmbito da organização sistemática dos serviços necessários à realização do cuidado em saúde (BARROS; SANTOS, 2020). 
Nesse período pandêmico, a SAE só poderá dar retorno satisfatório às questões emergentes, se fundamentada em referenciais da complexidade. Escolheuse, para tanto, a teoria da complexidade pela possibilidade de apreender a SAE como processo sistêmico e o cuidado como unidade complexa diante das questões emergentes na saúde, considerando a conexão entre o sujeito, seu contexto social e os serviços de saúde. Há interfaces dos saberes e práticas de enfermagem inerentes ao processo de cuidar, que se constitui complexo, de modo a ser compreendido e desvelado (MORIN, 2000).

Com base no exposto e a fim de visibilizar a atuação do enfermeiro face à pandemia provocada pela Covid-19, o presente estudo objetivou discorrer sobre os passos Sistematização da Assistência de Enfermagem, a partir de um relato de Enfermeiro da linha de frente da Covid-19, publicado em jornal local.

\section{METODOLOGIA}

Trata-se de um estudo qualitativo exploratório, realizado a partir de uma pesquisa em sites públicos e abertos. A pesquisa exploratória permite a ampliação de temáticas ou problemas e, ainda, pode indicar a necessidade de trabalhar os problemas com outros métodos (MINAYO, 2008). Sob esse enfoque, foi selecionado um depoimento de uma profissional de enfermagem que atua diretamente no combate à Covid-19. O depoimento da profissional Enfermeira foi extraído do site oficial da Unimed, no dia 17 de maio de 2020, dentre outros tantos depoimentos. Estas publicações têm se mostrado frequentes neste período de pandemia, sobretudo, pela luta por 30 horas semanais de trabalho, melhores condições de trabalho dentre outras reivindicações, as quais ganharam notoriedade, no Brasil, a partir do mês de março, conforme evidenciado no próprio site.

O relato foi selecionado pelo seu impacto profissional em período de pandemia. O mesmo servirá de inspiração para realizar a Sistematização da Assistência de Enfermagem, na perspectiva da teoria da complexidade, a qual serviu de suporte para a realização das diferentes etapas da SAE. Após a definição da temática e a escolha do relato profissional, procedeu-se com a sua leitura, organização e a análise, de modo a detalhar os passos da SAE. 


\section{RESULTADOS E DISCUSSÃO}

Os resultados serão detalhados a partir das cinco etapas da SAE, quais sejam: histórico de enfermagem; diagnóstico de enfermagem; planejamento de enfermagem; implementação de enfermagem; avaliação de enfermagem. Buscou-se transcender, neste estudo, a taxonomia NANDA e realizou-se o diagnóstico de enfermagem à luz da teoria da complexidade.

\section{Histórico de enfermagem}

Na sequência será apresentado o relato público da enfermeira que atua na linha de frente neste período de pandemia, o qual foi selecionado pelo seu impacto e número de acessos nas redes sociais.

"Meu nome é Paola Braz de Abreu, tenho 31 anos, sou enfermeira e atualmente trabalho no Hospital Unimed Chapecó, na UTI Covid. Quando escolhi ser enfermeira, jamais pensei que pudéssemos vivenciar o que hoje estamos vivendo, mas a cada dia que passa eu acredito mais e mais que escolhi a profissão correta. Escolhi ser enfermeira ainda criança, sem um motivo especifico, sem também saber o que fazia este profissional, eu só sabia que queria cuidar das pessoas. Simplesmente sabia que deveria ser assim. Estudei, me formei e comecei a trabalhar em um hospital público no Rio Grande do Sul, próximo da minha família, onde atuei durante 9 anos. E, em busca de mais oportunidades, em dezembro de 2019 eu, meu esposo e meus filhos de 7 anos nos mudamos para Chapecó. No início do ano ouvíamos muito falar do coronavírus em outros países, e já começava a avançar pelo mundo, mas como imaginar que ele chegaria até nós? Foi então que na metade de março do dia para noite, as escolas fecharam, as pessoas enlouqueceram a comprar comida para estocar e de repente em uma manhã saio para trabalhar e não encontro ninguém nas ruas. Então a ficha caiu! É verdade! E agora? Estou longe dos meus pais! Minha cunhada está grávida e eu não verei eles? Mas e meus filhos e meu marido, como vou voltar para casa? E se eu contaminar eles? $E$ todas essas dúvidas e inseguranças foram tomando conta. Na metade de março surgiu o primeiro paciente confirmado. Veio para UTI, mudou nossa rotina por completo. Usamos máscara o dia todo, cansa, machuca, ficar com os óculos de proteção o tempo inteiro é desconfortável, mas é necessário. Sempre após o plantão tomava banho no hospital, chegava em casa tomava outro banho. Me afastei dos meus filhos e meu esposo, pedi que ele fosse para o quarto de hóspedes e reservei a suíte com meu canto de isolamento, e lá sozinha os pensamentos voavam... "será que eles não deveriam voltar para o Sul, para o interior que é mais seguro que ficarem aqui comigo?", "será que se eles forem eu aguento ficar sozinha aqui, e se eu fico doente, quem vai me ajudar? Afinal nem deu tempo de estabelecer vínculos aqui", "seria muito egoísta da minha parte querer que eles ficassem na mesma casa que eu?". Saía do quarto somente quando necessário, deixava separado para mim o copo, o prato e os talheres, para que eles não tivessem contato comigo. Nosso primeiro paciente deu alta! Após, realizamos testes e não estávamos contaminados. Pedi uma folga e fui para casa dos meus pais. Estava mais tranquila, menos paranoica, pude abraçar meus filhos novamente, afinal eu não havia contraído nada. No final de abril a demanda aumentou. Então foi montado uma UTI em outro espaço físico só para atender os pacientes Covid, logo pedi para fazer parte desta unidade, pois eu me preparei durante este tempo em que me isolei em casa, li muito, estudei. Juntos, pensamos como vamos fazer para entubar os pacientes? Qual a melhor maneira de 
fazer sem nos expor? Como agir nos casos mais graves? Sempre estive em torno de todo o preparo, pois eu queria estar lá, queria fazer parte dessa equipe e penso sempre que tudo na vida tem um propósito! Por algum motivo eu vim parar em uma cidade desconhecida quando tudo isso começou! Recebemos treinamentos de tudo, como nos paramentar, como nos proteger, como atuar com o paciente, quais os materiais a serem utilizados em determinadas situações... Treinei a minha equipe, e estávamos prontos. Os pacientes começaram a chegar devagar. Estávamos cada dia mais preparados para estar lá. A demanda começou aumentar, as complicações também, vemos pacientes jovens e até idosos, ambos graves e longe dos seus familiares. Fico muito triste mas faço o que está ao meu alcance para que eles se sintam confortáveis, protegidos e amparados. Quanto à rotina familiar, estamos recebendo do hospital acompanhamento psicológico, o que nos deixa mais tranquilos. Coletamos exames de tempo em tempo para termos certeza que não estamos doentes. Hoje minha rotina diária é apenas ir trabalhar, e na folga fico em casa, não saio, não vou ao mercado nem a farmácia, pois tenho medo de adquirir a doença e não poder estar na linha de frente, assim como de estar assintomática e transmitir a outras pessoas. Não me isolo mais da minha família, pois já entendi que eles são o meu porto seguro, mesmo que um de nós fique doente, seria impossível os demais não ficarem. E também me sinto protegida no ambiente de trabalho. Sei que é cansativo passar $12 \mathrm{hs}$ direto com toda aquela paramentação necessária, mas diferente dos outros locais, eu sei que meu paciente tem Covid e eu sei que material usar para me proteger. Termino o plantão tomo banho no hospital, entre uma oração e outra chego em casa retiro os calçados na porta, entro dentro de casa com todo cuidado para que ninguém me toque e vou direto para o banho novamente, cuidados essências, e depois sento no sofá e penso, "será que fiz tudo certo?". Essa insegurança sempre nos persegue. E só o que queremos é que as pessoas se conscientizem, fiquem em casa, se saírem, usem máscara, lavem as mãos, mas saiam somente se necessário. Neste momento não é hora de aglomeração, de festas, junção de amigos, protejam suas famílias para que eu também possa proteger a minha".

A partir do relato da Enfermeira será apresentado, a seguir, o diagnóstico, o planejamento e a implementação de Enfermagem, os quais foram elaborados a partir do pensamento da complexidade.

Quadro 1: Diagnóstico, Planejamento e Implementação de Enfermagem

\begin{tabular}{|l|l|l|}
\hline Diagnóstico & Planejamento & Implementação \\
\hline $\begin{array}{l}\text { Consciência de estar na } \\
\text { linha de frente }\end{array}$ & $\begin{array}{l}\text { Promover reconhecimento } \\
\text { Profissional }\end{array}$ & $\begin{array}{l}\text { Posts de reconhecimento do ser } \\
\text { e fazer enfermagem }\end{array}$ \\
\hline Medo do desconhecido & $\begin{array}{l}\text { Ampliar o processo formativo } \\
\text { a partir do referencial } \\
\text { sistêmico }\end{array}$ & $\begin{array}{l}\text { Promover espaços de } \\
\text { discussão interprofissional }\end{array}$ \\
\hline Isolamento da família & Promover videochamadas & Disponibilizar Wi-fi para usuários \\
\hline $\begin{array}{l}\text { Rotina exaustiva de de } \\
\text { protocolos }\end{array}$ & $\begin{array}{l}\text { Desenvolver softwares que } \\
\text { dinamizam as informações }\end{array}$ & $\begin{array}{l}\text { Otimizar o processo drabalho a partir de tecnologias } \\
\text { virtuais }\end{array}$ \\
\hline Desconforto dos EPIs & $\begin{array}{l}\text { Criar EPIs mais confortáveis } \\
\text { e menos onerosos }\end{array}$ & $\begin{array}{l}\text { Ouvir e acolher a demanda dos } \\
\text { profissionais }\end{array}$ \\
\hline
\end{tabular}


No sentido de contribuir para uma maior visibilidade do ser e fazer enfermagem face à pandemia da Covid-19, foi elaborado um Card de orientações afirmativas, com vistas à redução dos efeitos deletérios.

Quadro 2: Card de orientações

\section{A ENFERMAGEM: ADAPTACG̃OO PANDÊMICA}

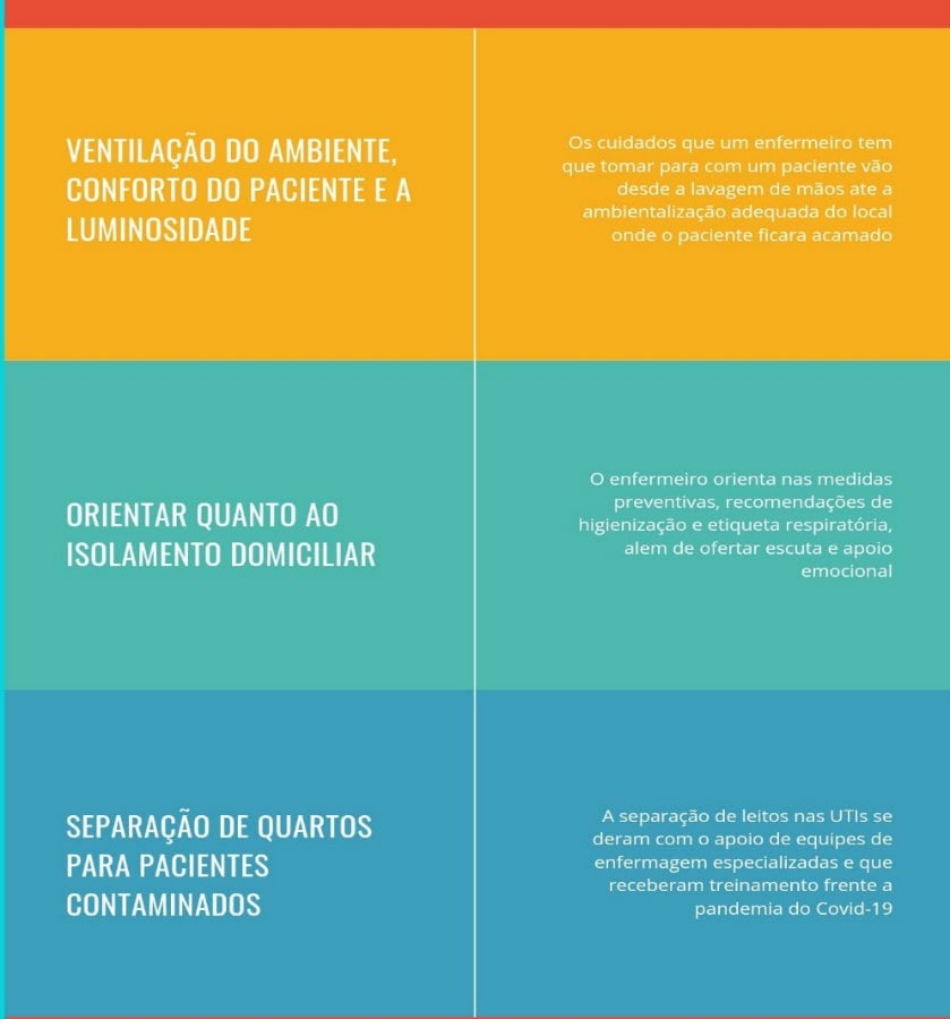

\section{CONSIDERAÇÕES FINAIS}

A Sistematização da Assistência de Enfermagem é capaz, a partir de um olhar ampliado e prospectivo, de possibilitar reflexões que transcendem o ser e fazer enfermagem face às adversidades da pandemia da Covid-19. Para além do fazer 
enfermagem é preciso considerar o ser profissional que está exposto, continuamente, à medos, angústias e incertezas.

É preciso considerar, também, que a desordem provocada pela Covid-19, a qual expos os profissionais aos diversos riscos, também possibilitou elementos para o fomento de uma nova organização profissional. Esta nova ordem já pode ser visualizada nos diversos depoimentos manifestações de homenagens aos Enfermeiros, os quais figuram, nesse combate biológico, como os principais heróis.

\section{REFERÊNCIAS}

BARROS, A. L. B. L., SANTOS, V. B. Contribuições da rede de pesquisa em processo de enfermagem para assistência na pandemia de COVID-19. Rev. Bras. Enferm. v.73, n.suppl 2, 2020. https://doi.org/10.1590/0034-7167-2020-0798

CRODA, J. H. R., GARCIA, L. P. Resposta imediata da Vigilância em Saúde à epidemia da COVID-19. Epidemiol. Serv. Saúde, v.29, n.1, p.23 https://doi.org/10.5123/S1679-49742020000100021

LÜDKE, M., MEDA, A. Pesquisa em educação: abordagens qualitativas [internet]. São Paulo: EPU; 1986 [acesso em 25 mai. 2020]. Disponível em: https://edisciplinas.usp.br/pluginfile.php/4247151/mod_resource/content/2/Lud_And_ cap3.pdf.

MINAYO, M.C.S. O desafio do conhecimento: pesquisa qualitativa em saúde. $11^{\text {a }}$ ed. São Paulo, HUCITEC, 2008.

Morin, E. Ciência com consciência. Rio de Janeiro: Bertrand, 2000.

SILVA, V. F. Enfermagem no combate à pandemia da COVID-19 Rev. Bras. Enferm. v. 73, n.Suppl 2), 2020. https://doi.org/10.1590/0034-7167

WU JT, LEUNG K, LEUNG GM. Nowcasting and forecasting the potential domestic and international spread of the 2019-nCoV outbreak originating in Wuhan, China: a modelling study. Lancet [Internet]. 2020 Jan [cited 2020 Mar 4];395(10225):689-97. Available from: Available from: https://doi.org/10.1016/S0140-6736(20)30260-9 » https://doi.org/10.1016/S0140-6736(20)30260-9 